\title{
AN INVESTIGATION ON LANE BLOCKAGE EFFECTS AT SIGNALIZED INTERSECTIONS
}

\author{
Kiarash Ghasemlou', Metin Mutlu Aydın' ${ }^{2}$, Mehmet Sinan Yıldırım ${ }^{3}$ \\ ${ }^{1}$ İstanbul Technical University, Department of Civil Engineering, 34469, İstanbul, Turkey \\ ${ }^{2}$ Gümüşhane University, Department of Civil Engineering, 29000, Gümüşhane, Turkey \\ ${ }^{3}$ Celal Bayar University, Department of Civil Engineering, 45030, Manisa, Turkey
}

Received 14 June 2016; accepted 1 August 2016

\begin{abstract}
Various factors (illegal parking, the existence of a bus stop, road surface deformations etc.) generally cause blockage on traffic flow at signalized intersections. These factors have a negative effect on capacity of signalized intersections. This study examines the blockage effect of a bus stop and a road surface deformation on capacity of a signalized intersection by implementing a Cell Transmission Model (CTM). Study has conducted extensive simulation experiments that captures traffic parametres and evaluates complex traffic flow interactions on signalized intersections using cell transmission concept. In analyses, boundary conditions were defined by means of input and output cells with infinite sizes and proper capacity values. It is assumed that vehicles have instantaneous acceleration and deceleration properties such as vehicles' movement or stop instantaneously from their current situation when encountered a bottleneck situation. The results of simulation experiments indicate that if blockage on traffic flow is far from the signalized intersections, negative effects on the capacity were decreased. Also results pointed that the dominant factor was considered as the distance between the surface deformation area/bus stop and signalized intersection for the capacity change.
\end{abstract}

Keywords: blockage effect, cell transmission model, signalized intersection, traffic flow.

\section{Introduction}

There are various factors that effects the performance of signalized intersections. Illegal parking, road surface deformations, the existence of a bus stop before the signalized intersections can be shown as some examples to this problem. These factors have a negative effect on capacity of signalized intersections. For example, bus stops near signalized intersections have a great effect on intersection capacities (Ghasemlou et al., 2012). Operational characteristics of buses in traffic may strongly affect the service quality and capacity of signalized and unsignalized intersections. There are several methods in literature to determine these effects (Wong et al., 1998; Rodriguez-Seda and Benekohal, 2006; Abdulsalam et al., 2015; Ghasemlou et al., 2015). Specifically, TRB (2010) suggests the implementation of a specific adjustment factor to reflect the adverse effects of the operational characteristics. According to TRB (2010), "if there is a bus stop which is so close to a signalized intersection, a correction factor $\left(f_{b b}\right)$ is used to determine capacity". Particularly, the negative effects of stopped bus for boarding or alighting passengers can be represented by a bus-blockage adjustment factor $\left(f_{b b}\right)$. This factor represents the

\footnotetext{
${ }^{2}$ Corresponding author: metinmutluaydin@gumushane.edu.tr
} 
influence of a bus which operationally stops at the near or far side of a bus stop within either $76.2 \mathrm{~m}$ upstream or downstream of the stop line (TRB, 2010). According to $f_{b b}$ equation of TRB (2010), $14.4 \mathrm{~s}$ (a constant value) was calculated according to dwell time of buses as a coefficient. But this value does not reflect a reliable estimation due to the regional variability (Ghasemlou et al., 2012). Additionally, the HCM does not examine and evaluates influences of the geometric standards of bus stop and roads on behaviors of drivers for these conditions. TRB (2010) only calculates the value of $f_{b b}$ depending on the number of buses in a green period passed. Also, regional and geometric factors were evaluated for the $f_{b b}$ equation suggested by (TRB, 2010). Rodriguez-Seda and Benekohal (2006) stated that HCM (TRB, 1950) identified the differences of operational characteristics in moving and stopping buses by accepting all stopping busses have the same influence (equals to three or five passenger cars) on intersection capacity (Rodriguez-Seda and Benekohal, 2006; TRB, 2010; TRB, 1950). The 1965 edition of HCM stressed the adverse effect of operational buses considering the signalized intersections and proposed several approaches to adjust for each type of bus stops (Ghasemlou et al., 2012; RodriguezSeda and Benekohal, 2006; TRB, 1965). The stopping and moving (transit) buses differ according to their characteristics in a traffic flow (Amita et al., 2015; Alex and Isaac, 2014). Stopping buses cause delays at a bus stop for serving the passengers for a period of time which is called dwell time. Moreover, additional delay should be considered as the acceleration and deceleration of the bus for approaching and departing from the bus stop (Rodriguez-Seda and Benekohal, 2006). A specific location of a bus stop directly affects the speed and capacity of a bus. For example, far-side stops are considered superior to alternative locations with reflecting the minimal adverse effect on the speed and capacity. Moreover, mid-block stops have better options considering near-side stops. However, lane position of a bus stop is another vital factor that affects how easily a bus returns to its route in traffic. Two bus stop positions were considered as on-line (bus typically stops in lane) and off-line (bus stops at a special parking or pullout) which were defined by the TCQSM (2013). Online position is considered as superior as the bus may be able to resume its route as soon as boarding (TCQSM, 2013; Ghasemlou et al., 2014).

Another important parameter that affects the performance of signalized intersections is the road surface deformation effect of buses at bus stops. Road surface deformations are defined as any change on a pavement surface compared with the initial state of construction along the service life (Aydin et al., 2013). A road is designed and built with a predicted load carrying capacity for a service life (Ben-Edigbe and Ferguson, 2005). But after opening for traffic, many physical deformations begin to form on surface caused by excessive traffic loads and different environmental effects (Aydin et al., 2014; Aydin and Topal, 2016). Some of these deformation types are particularly observed at signalized intersections such as rutting, broken edges, cracking, loose aggregates, swelling and shoving caused by accelerating/decelerating behaviors of vehicles and bus stop effects. Deformations may negatively affect the performance of signalized intersections in relation to their position and size. To determine the negative effects of these deformations Ben-Edigbe et 
al. (2011) tried to explore trapezoidal flow rate contractions resulting from surface deformations. They reported that there is an important difference in vehicle speed between "with" and "without" deformation areas. In another study, Ben-Edigbe and Ferguson (2009) measured the quantity of negative effects. Study results indicate that surface deformations reduce road capacity and speed of vehicles $30 \%$ and $20 \mathrm{~km} / \mathrm{h}$, respectively. Also in another similar study, Ben-Edigbe (2010) reported that adverse conditions have a significant impact on level of road service. Also he found significant reduction in speed by up to $50 \%$ and in traffic flow by up to $20 \%$ would result from pavement surface deformations. However, the results of conducted some studies showed that deformations on pavement surfaces may reduce speeds average $6 \mathrm{~km} / \mathrm{h}$ (TRL, 1991).

Previous studies about blockage effect on capacity signalized intersections have been vey limited. They generally focused on examining the capacity of signalized intersections by considering geometric properties of intersections, traffic flow properties, lane and driver charactaristics etc. But this study aims to investigate the relation between blockage of traffic flow and signalized intersection capacity. For this purpose a macroscopic model called the Cell Transmission Model (CTM) was implemented in analysis to design an alternative method for predicting the the blockage effect of traffic flow caused by a bus stop or a road surface deformation at a signalized intersection. To reach focused aim, different methods for the prediction of bus or deformation blockage effect due to a stoppage were investigated and compared under different conditions.

\section{Model Structure of Cell Transmission}

Simulation of traffic problems is an important method for investigating and proposing potential solutions. Simulations of congested and oversaturated traffic conditions are not considered as a trivial task and many available methods do not adequately establish a model structure for these conditions. Therefore, in order to improve current traffic flow models, some simulation methods are necessarily implemented for an adequate study of such a signalized intersection. The cell transmission model (CTM) is a potential traffic simulation method to determine a traffic flow effect at a signalized intersection. CTM is a comprehensive numerical analysis method suggested by Daganzo (1994) to simulate Kinematic Wave Model of Lighthill and Whitham (1955). CTM predicts macroscopic and microscopic traffic behaviour of vehicles on a given road length by analysing flow and density of a traffic at different time steps (Lighthill and Whitham, 1955; Richards, 1956; Gomes and Horowitz, 2006; Gomes et al., 2008; Dong et al., 2012; Zhang et al., 2013). CTM divides road sections into several homogeneous cells and simulates traffic conditions on a road corridor by proposing to system where every new situations are updated with time (Daganzo, 1993). The advantages of CTM was summarized by Tampère et al. (2011) as simple structure, high capacity to capture different traffic phenomena and ability to model different phenomena boundary with cells. These cells were identified as origin, destination, merge, diverge, and general intersection (Tempere et al., 2011). CTM are necessary to simulate real traffic problem phenomena and based on that density $(k)$ and traffic flow $(q)$ have a linear relationship as shown in Fig. 1. 


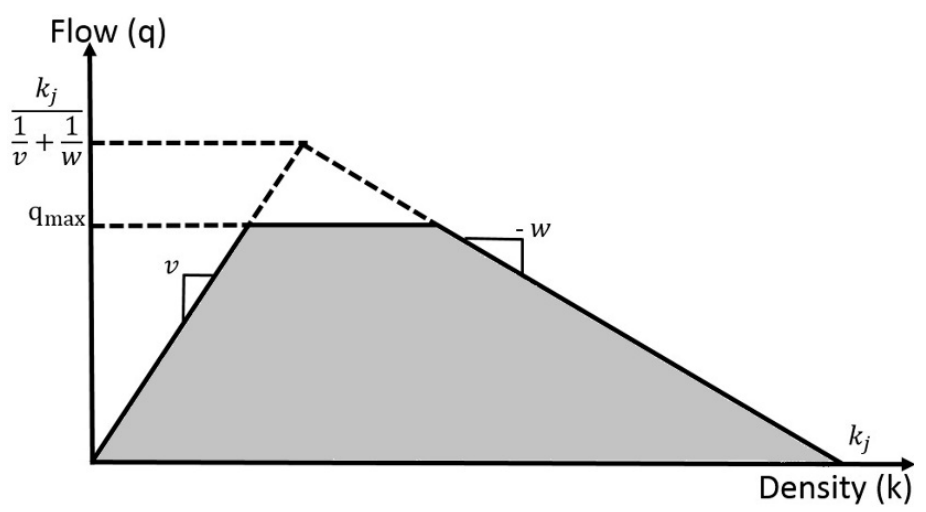

Fig. 1.

A Trapezoidal Fundamental Graph for CTM

Source: Daganzo (1995)

Eq. (1) expresses the traffic flow between two neighbour cells in a cell transmission model (Daganzo, 1995).

$q=\min \left\{v k, q_{\max }, w\left(k_{j}-k\right\}\right.$, for $0 \leq k \leq k_{j}$

Where; $v$ : the free-flow vehicle speed of a vehicle $(\mathrm{km} / \mathrm{h}), q_{\max }$ : the maximum flow (capacity) (veh/hrr), w: the backward forming wave speed $(\mathrm{km} / \mathrm{h}), k_{j}$ : jam (maximum) density (veh/ $\mathrm{km}), v$ : a constant value under low traffic density. According to Eq. (1) if density value of a traffic flow is high, $w$ : a constant value and $v>w$, For $0 \leq k \leq k_{j}$ the Eq. (1) is provided. From Eq. (1) moving process of the traffic flow among cells can be illustrated in Fig. 2 .

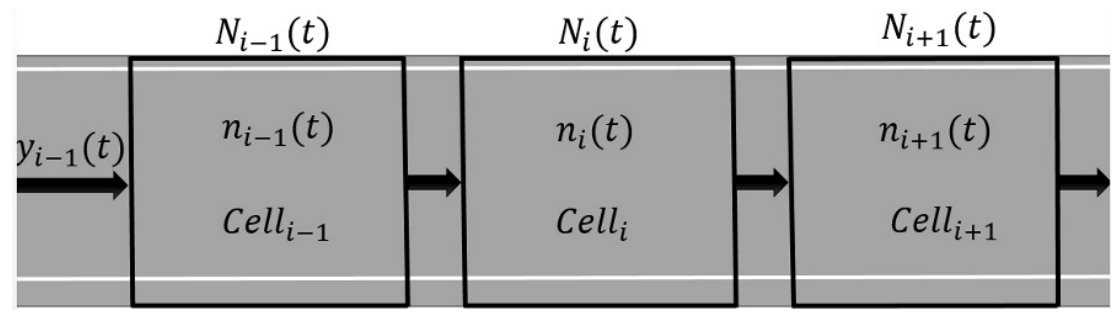

Fig. 2.

Flow Advancement Model of CTM

Where; for each time step, $y_{i}(t)$ : the total value of traffic flow (veh/hr) incoming the cell $i ., N_{i}(t)$ : the highest traffic flow in cell $i$ (veh/hrr), $n_{i}(t)$ : vehicles in the cell $i$ (veh/hr), $q_{i}(t)$ : the incoming flow rate flow of the cell $i$, $q_{i} \cdot \max (t)$ : the highest incoming flow rate for cell $i$. The connection between vehicles and density in a cell can be described as Eq. (2):

$n_{i}(k)=k_{i}(k) v \delta$

Where; $\delta=w / v$. If cells of model are consecutively numbered starting with the end of the upstream road from $i=1$ to 
$n$, repetitive relation of the CTM can be written as:

$n_{i}(t+1)=n_{i}(t)+y_{i}(t)-y_{i-1}(t)$

$n_{i}(t)=\min \left\{n_{\mathbf{i}-1}(t), Q_{\mathbf{i}}(t), \frac{w\left(N_{i}(t)-n_{i}(t)\right.}{v}\right\}$

Where; $n_{i}(t)$ : incoming flow to cell $i$ in the time interval $(t, t+1), Q_{i}(t)$ : the maximum flow (capacity) rate of cell $i$.

The movement of vehicles in a road section can be examined as traffic flow transmission inside road sections and between the neighbour sections. Recent some studies used Daganzo's CTM to examine traffic flow movements which includes node model
(NM) and road section model (RSM). In NMs, lanes and signal timing control are located at the end of the road section (Gomes and Horowitz, 2006; Gomes et al., 2008; Li, 2010; Dong et al., 2012). According to the NM, developed (RSM) is suggested with oriented cell instead of NM into section model to have better understanding the movement of vehicles (Gomes and Horowitz, 2006; Gomes et al., 2008; Dong et al, 2012). It simplifies modeling process and improves accuracy of calculation. The maximum flow and outgoing flow of oriented cells is determined by signal plan of downstream. Thus, important factos on oriented cell are varied caused by various routes. Considering group selection of a lane, $C_{m}^{L}$ and $C_{m}^{R}$ can be described as traffic a traffic flow's two types of oriented cells (Fig. 3).

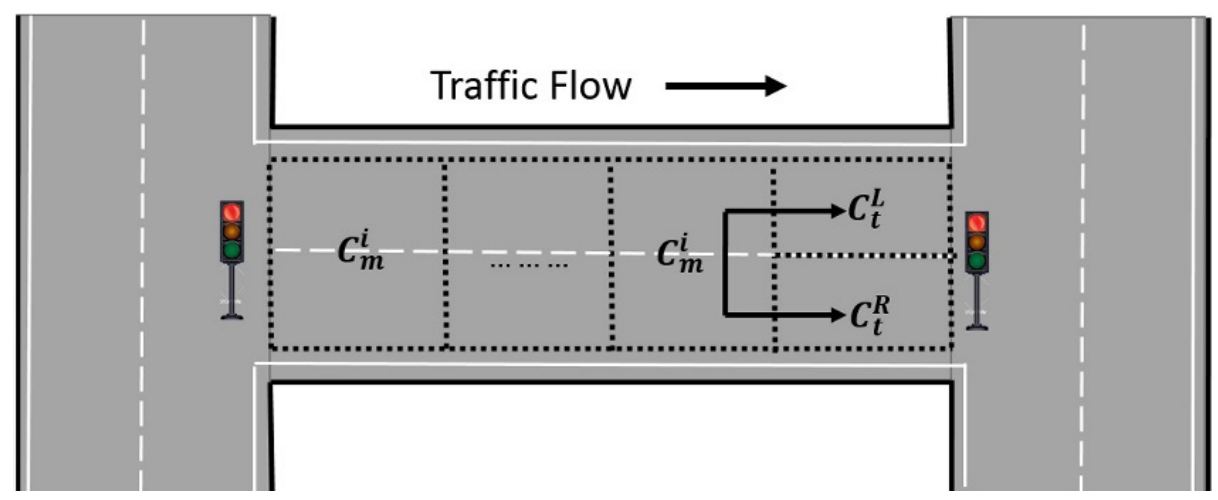

Fig. 3.

Flow Transmission between Cells

Section $m$ has ordinary cells $C_{m}^{i}(i=1,2,3 \ldots, n)$ and a series of oriented cells through a traffic direction. According the CTM theory, first two types of traffic flow transmission between cells can be used in lane blockage analysis. These two types can be classified as given below (Gomes and Horowitz, 2006; Gomes et al., 2008; Dong et al., 2012):
Flow description of ordinary cells in a road link (Fig. 3).

Flow description of ordinary andoriented cells in a road link (Eq. (5) and Eq. (6)). It defines that vehicles in ordinary cell moves into different oriented cells based on trip demand (Fig. 3). 


$$
\begin{aligned}
& y_{a}^{L}(t)=\min \left\{n_{a}^{m}(t), Q_{a}^{L}(t), \frac{w\left[N_{a}^{L}(t)-N_{a}^{L}(t)\right]}{v}\right\} \\
& y_{a}^{R}(t)=\min \left\{n_{a}^{m}(t), Q_{a}^{R}(t), \frac{w\left[N_{a}^{R}(t)-N_{a}^{R}(t)\right]}{v}\right\}
\end{aligned}
$$

\section{Analysis of Simulation Experiments and Findings}

In simulation experiments, road distance was taken as 500 meters considering the speed of vehicles and numbers of cells. Two dummy cells were used to identify the entry and exit cells. The density and capacity of these cells were defined as finitely big numbers. The total number of cells for the model was determined by summation of the cells through the road distance with the entry and exit cells. In the analyses, each time step was considered as 1 second. In addition, the number of cars passing through to the end of the road was considered as the sum of cars passing at the end of a period in one hour. During the analysis, with the replacement of the signal location through the first cell to the last, the near and far side effects of the deformation and bus stop locations were investigated. Considering the substantial effect of signal duration, various capacity values were determined according to the characteristics of each green period for bus stop effect and cycle period for deformation effect. The total number of steps was determined by dividing the total seconds in an hour (3600 s) to the time needed to pass one cell ( $1 \mathrm{~s})$. The analyses were carried out for each single cell with considering a cycle period of 60 seconds and also three blockage and green time values were used (20,30 and 40 seconds). The distances from the road surface deformations and bus stops to the signalized intersection were individually evaluated for each cell. Signalization was not included in the first five cells. If the signal is located in the first four cells, there would be not enough space behind the signal so unreal queue will be observed. This situation will result in loss of the vehicle number used in the analyses. The key elements of the CTM were the length of a cell and the speed of a vehicle at free flow conditions. All the model inputs were generated and calculated in the MATLAB $^{\circledR}$ software.

\subsection{Bus Blockage Effect}

To understand the influence of the bus stops on the signalized intersections various parameters (deviation of the speed, dwell time, distance between bus stop and signalized intersection and standard deviation of dwell time) were investigated in the bus blockage model. Then the following assumptions were made;

- There is only one bus in the bus stop,

- Busses pass through the intersection,

- Accelerations and decelerations of the buses effect only right lane,

- There is no extra bus bay.

Also in the scope of analysis, it was assumed that total 60 busses arrive during in one hour. $50 \%$ of busses arrive at green phase and other $50 \%$ come in red phase. The free flow approach speeds of the buses were considered as $40 \mathrm{~km} / \mathrm{h}$ and $70 \mathrm{~km} / \mathrm{h}$. It was assumed that road is formed as two lane and left lane wasn't blocked by a bus. Also road density was defined as 180 vehicle/ $\mathrm{km} /$ lane. Movement of vehicles, cells and bus on a signalized intersection is shown in Fig. 4. Input parameters of simulated model cells for bus blockage effect is summarized in Table 1. 


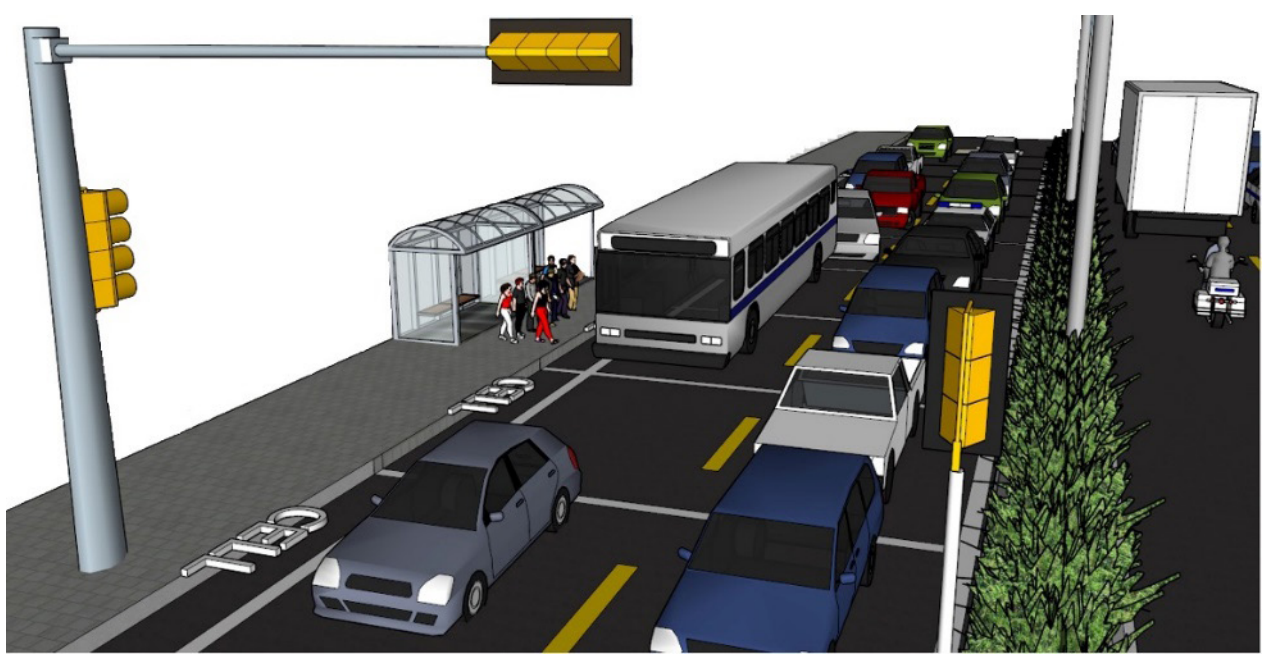

Fig. 4.

Bus Blockage Effect

Table 1

Parameters of Simulated Model Cells for Bus Stop Effect

\begin{tabular}{|c|c|c|c|c|c|c|}
\hline $\begin{array}{l}\text { Speed } \\
(\mathrm{km} / \mathrm{h})\end{array}$ & $\begin{array}{l}\text { Green/Cycle } \\
\text { (sec.) }\end{array}$ & $\begin{array}{l}\text { Total Delay (Except } \\
\text { Acceleration / } \\
\text { Deceleration) } \\
\text { (sec.) }\end{array}$ & $\begin{array}{l}\text { Total Number } \\
\text { of Cells } \\
\text { (N) }\end{array}$ & $\begin{array}{l}\text { Location of } \\
\text { Bus Stop } \\
\text { (Cell) }\end{array}$ & $\begin{array}{l}\text { Cell Length } \\
\text { (m) }\end{array}$ & $\begin{array}{l}\text { Delay } \\
\text { (Acceleration/ } \\
\text { Deceleration) } \\
\text { (sec.) } \\
\end{array}$ \\
\hline \multirow{3}{*}{70} & $20 / 60$ & \multirow{3}{*}{$(20-30-40)$} & \multirow{3}{*}{27} & \multirow{3}{*}{16} & \multirow{3}{*}{18.5} & \multirow{3}{*}{17} \\
\hline & $30 / 60$ & & & & & \\
\hline & $40 / 60$ & & & & & \\
\hline \multirow{3}{*}{40} & $20 / 60$ & \multirow{3}{*}{$(20-30-40)$} & \multirow{3}{*}{47} & \multirow{3}{*}{28} & \multirow{3}{*}{10.6} & \multirow{3}{*}{11} \\
\hline & $30 / 60$ & & & & & \\
\hline & $40 / 60$ & & & & & \\
\hline
\end{tabular}

According to the 10.6 meter length for each cell model was consisted of 47 cells for $40 \mathrm{~km} / \mathrm{h}$ and 27 cells for $70 \mathrm{~km} / \mathrm{h}$ (except entry, exit and bus stop cell). In the model, 28 th cell for $40 \mathrm{~km} / \mathrm{h}$ and $16 \mathrm{th}$ cell for $70 \mathrm{~km} / \mathrm{h}$ was dedicated for the location of the bus stop. According to the position of signal capacity variation for the end of the section is shown in Fig. 5. It was seen from the analyses, if the bus stop was located far from the signalized intersections, negative effects of bus stops on capacity were decreased (Fig. 5). The dominant factor was considered as the dwell time and distance between the bus stop and signalized intersection. It can be argued that the green ratio and dwell time should be considered to clarify impact of bus blockage. It could be seen from the Fig. 5 , in some cases, bus station has no effect on the capacity of intersection due to small dwell time value. According to the main parameter of dwell time (user demand), dwell time distribution could be changed. 

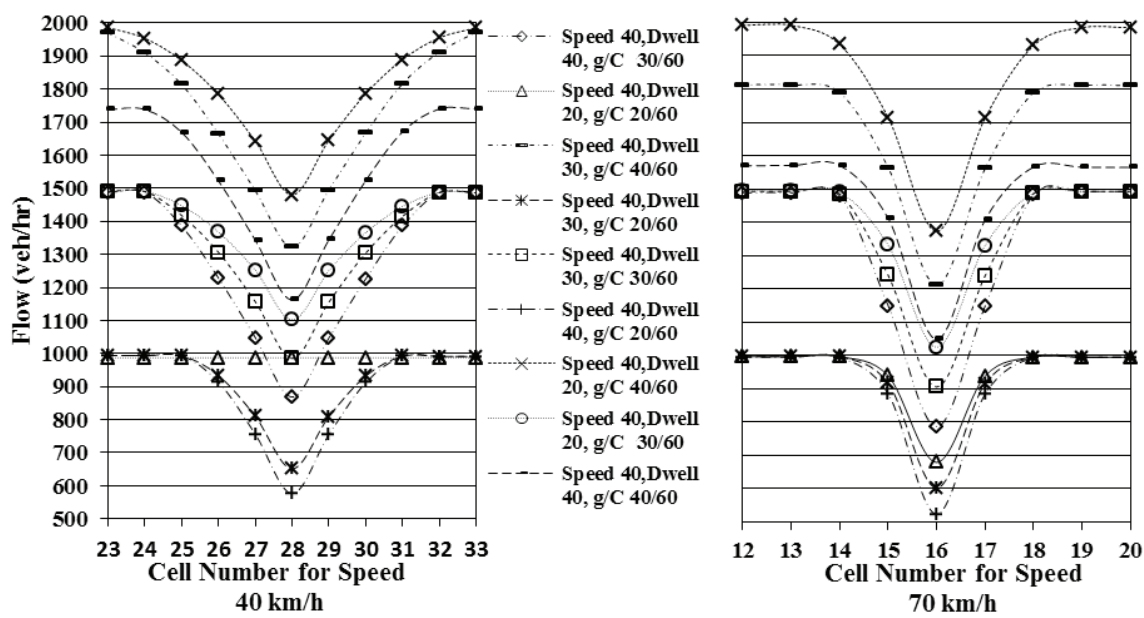

Fig. 5.

Capacity Value According to Signal Distance from the Bus Stop and Green Time Ratio for $40 \mathrm{~km} / \mathrm{h}$ and $70 \mathrm{~km} / \mathrm{h}$ Speed

Also comparison results of the (HCM, 2010) and the CTM model showed that the CTM model was more effective for distance between signal and position of bus station (Fig. 6). It was seen from Fig. (5) and
Fig. (6), if bus stop is located far from the signalized intersections, negative effects of surface deformations on the capacity and bus-blockage adjustment factor $\left(f_{b b}\right)$ were decreased.

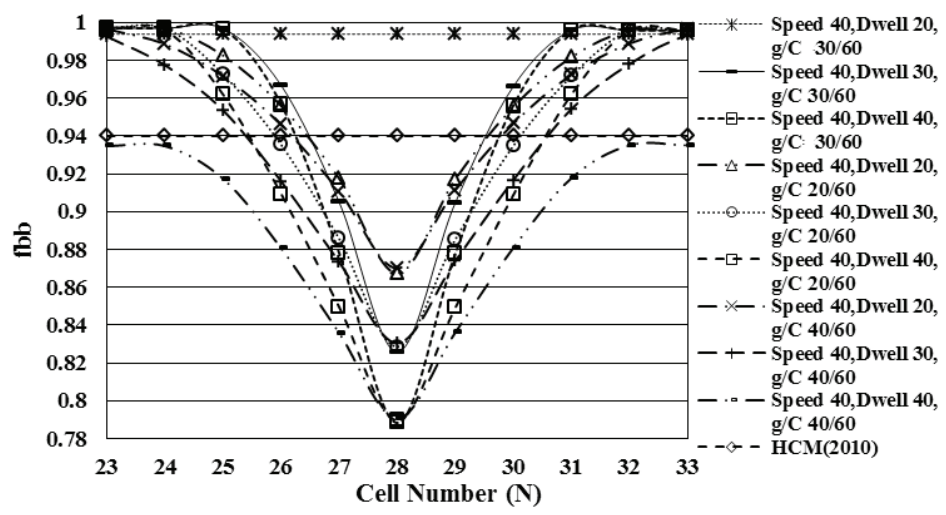

Fig. 6.

Comparison of the CTM Model and the HCM Equation Results

This research represents the first step to investigate the effect of standard deviation of the bus blockage time on the capacity of signalized intersections. For further research, this model could be extended with effect of the coefficient of variation, bus stop type and impact of lane changing behind a bus on a bus stop. Also, by using 
this model, different correction coefficients can be derived instead of $14.4 \mathrm{sec}$. for several situations.

\subsection{Road Surface Deformations Effect}

In order to find negative effects of surface deformations on signalized intersections by using CTM, principally following parameters were investigated:

- Deviation of the green time ratio in a phase,

- The blockage effect (\%) of surface deformations (100\% full blocking; $60 \%$ and $30 \%$ partial blocking a lane),

- Distance effect between surface deformation and signalized intersection.

For the study, the following assumptions were made;
- Road consists of two lanes,

- Single surface deformation area,

- Surface deformation can be located on the right or left lane and only one lane can be affected from deformation,

- Extent of capacity loss on lanes resulting from lane changing effects of vehicles is not taken into the account.

The free flow approach speeds $\left(v_{f}\right)$ were considered as $40 \mathrm{~km} / \mathrm{h}$. It is assumed that road is formed as two lane and only one lane blocks according to the deformed area characteristics (100\% full blocking; $60 \%$ and $30 \%$ partial blocking a lane). Also road density was considered as 180 vehicle $/ \mathrm{km} /$ lane. Movement of vehicles, cells and a road surface deformation on a signalized intersection is shown in Fig. 7. Also input parameters of simulated model cells for road surface deformation effect is summarized in Table 2.

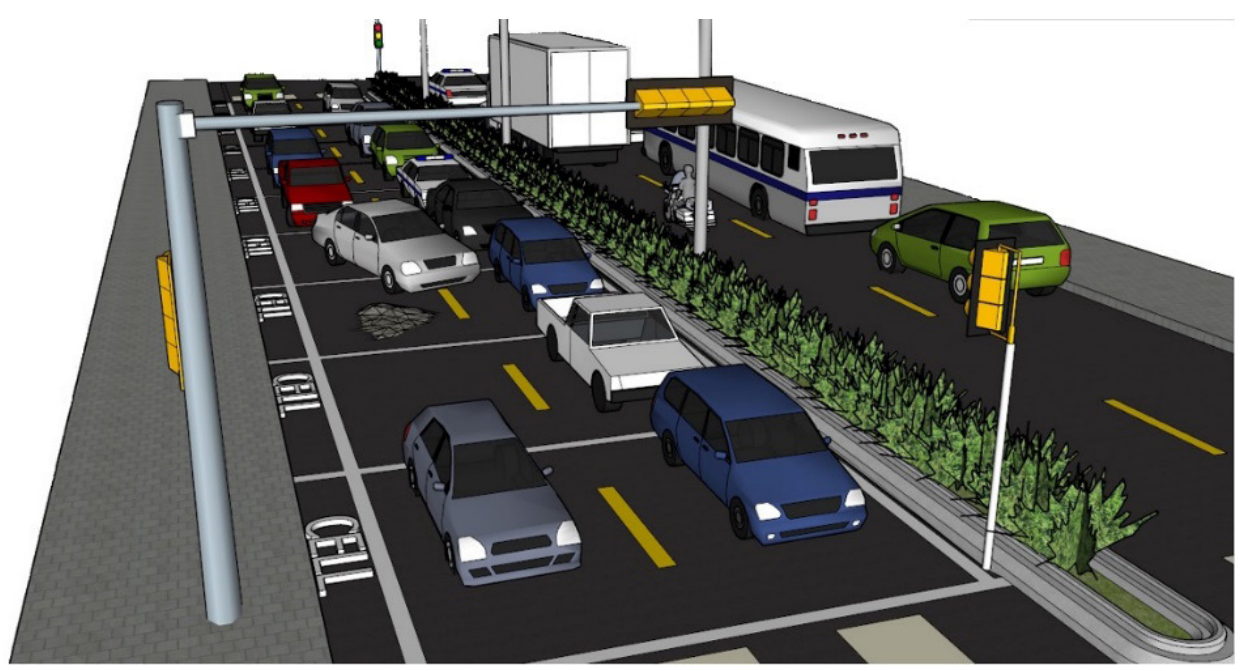

Fig. 7.

Blockage Effect of Road Surface Deformation 
Table 2

Parameters of Simulated Model Cells for Road Surface Deformation Effect

\begin{tabular}{|l|l|l|l|l|l|}
\hline $\begin{array}{l}\text { Speed } \\
(\mathbf{k m} / \mathbf{h})\end{array}$ & $\begin{array}{l}\text { Green/Cycle } \\
(\mathbf{s e c})\end{array}$ & $\begin{array}{l}\text { The blockage effect of } \\
\text { surface deformations } \\
(\%)\end{array}$ & $\begin{array}{l}\text { Total Number } \\
\text { of Cells } \\
(\mathbf{N})\end{array}$ & $\begin{array}{l}\text { Location of Deformation } \\
\text { Area } \\
(\text { Cell Number })\end{array}$ & $\begin{array}{l}\text { Cell } \\
\text { Length } \\
(\mathbf{m})\end{array}$ \\
\hline \multirow{3}{*}{40} & $20 / 60$ & $(100-60-30)$ & 45 & 28 & 11.11 \\
\cline { 2 - 6 } & $30 / 60$ & & & \\
\cline { 2 - 6 } & $40 / 60$ & & & \\
\hline
\end{tabular}

According to the 11.11 meters length for each cell model was consisted of 45 cells for $40 \mathrm{~km} / \mathrm{h}$ (except entry, exit and bus stop cell). In the model, $28 \mathrm{th}$ cell for $40 \mathrm{~km} / \mathrm{h}$ dedicated for the location of deformation area. The capacity change $(\mathrm{v} / \mathrm{hr})$ at the end of the section according to position of signals is shown in Fig. 8.

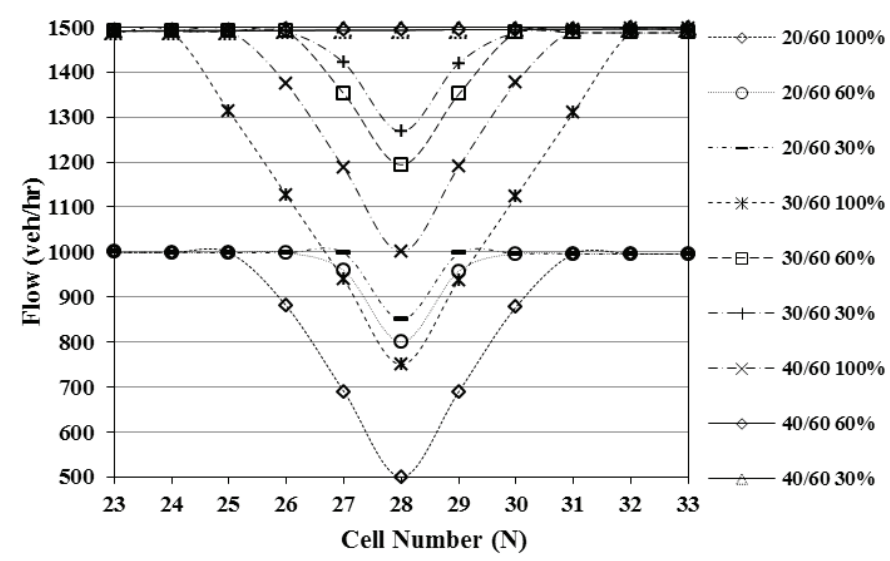

Fig. 8.

Capacity Value According to Signal Distance from the Deformed Area and Green Time Ratio for 40 $\mathrm{km} / \mathrm{h}$ Speed

In analyses, boundary conditions were defined by means of input and output cells with infinite sizes and proper capacity values. It can be seen from the results that each cell has an independent behaviour and order. This situation occurs due to the vehicle number which enter a cell is unrelated to the total vehicle numbers leaving from the cell. Every cell only affected by the current flow situation of the cell. Also, it should be noted that it is hard to investigate acceleration and deceleration behavior of vehicles because of the aggregate nature of road. In this study, it is assumed that the vehicles have instantaneous acceleration and deceleration properties such as vehicles start or stop instantaneously from their current situation when encountered by bottlenecks like signalized intersections or stop lines etc. (Daganzo, 1994). Additionally, entrance to a specific cell was directly influenced by the current traffic conditions. To indicate the effect of bottleneck caused by the deformation 
area, deformation area's cell capacity was reduced. For transforming the traffic flow at the each condition with an adjustment factor $\left(f_{d}\right)$, each case was subdivided to their own ideal capacity. Blockage effect (full blocking; $60 \%$ and $30 \%$ partial blocking) of a road surface deformation was taken into account to determine the capacity change and an adjustment factor $\left(f_{d}\right)$ for the capacity calculation. Fig. 9 illustrates the influence of the adjustment factor $\left(f_{d}\right)$ for each signal location and case.

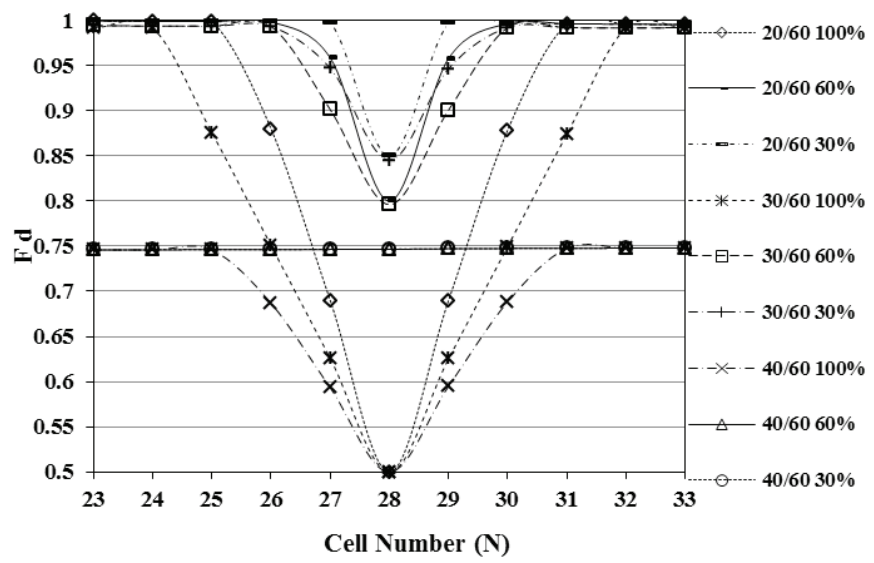

Fig. 9.

Adjustment Factor $\left(f_{d}\right)$ Value for Each Signal Location and Cases for $40 \mathrm{~km} / \mathrm{h}$ Vehicle Speed

It was seen from the analyses, if the road surface deformation is located far from the signalized intersections, negative effects of surface deformations on the capacity were decreased (Fig. 9). Also results pointed that the dominant factor was considered as the distance between the surface deformation area and signalized intersection for the capacity change. It can be argued that the green ratio and blockage time should be considered to clarify impact of road surface deformation blockage effect. It could be seen from the figures; in some cases deformation has no effect on the capacity of intersection due to the small blockage time value. Especially, due to the stoppage of vehicles during the green phase, a great distance is expected between the deformation and the vehicle behind the deformation area. In the light of the results obtained from the analysis if the surface deformation effect is bigger than the signalized intersection's green time ratio, stream capacity can be defined by deformation area location. In other words, deformation area can be defined as the bottleneck of a stream. In traffic simulation research and studies, the utilization of this result may lead to attract attention of road surface deformation on capacity and blockage calculations on a deformed road.

\section{Conclusions and Evaluations}

In this study a typical macroscopic cell transmission model was implemented in analysis to design an alternative method of predicting the effect of bus blockage and road surface deformations at signalized intersections. For this purpose, different 
methods for the prediction of an effective bus and road surface deformation blockage effect due to a stoppage were investigated and compared with different conditions. Based on the data analysis it can be concluded that:

- The simulation results are independent from the order in which the cells are examined at each step.

- There is no single relation between the number of vehicles entering a cell and number of leaving vehicles from it.

- If the road surface deformation or bus stop is located far from the signalized intersections, negative effects of surface deformations on the capacity were decreased. The dominant factor in this result is the distance between the surface deformation/bus stop and signalized intersection for the capacity change.

- In some cases deformation has no effect on the capacity of intersection due to the small blockage time and bus stop has no effect on the capacity due to small dwell time value.

- Comparison results of the HCM (2010) and the CTM model showed that the CTM model was more effective for distance between signal and position of bus station

- If bus stop is located far from the signalized intersections, negative effects of surface deformations on the capacity and bus-blockage adjustment factor $\left(f_{b b}\right)$ were decreased.

In this study some factors are not taken into the account in analyses such as extent of capacity loss on lanes resulting from lane changing effects of vehicles, vehicle lengths, vehicle types, different lane number, different lane width and different flow speed effects. The future studies need to reflect and clarify different assumptions and parameters and to suggest further ways to estimate the blockage effect of road surface deformations and bus stops on a signalized intersection capacity.

\section{References}

Abdulsalam, A.J.; Hassan, Y.; El Halim, A.A. 2015. The effect of automated speed cameras on fatal traffic collisions in Kuwait, Journal of Engineering Research, 3(4): 17-29.

Alex, S.; Isaac, K.P. 2014. Traffic simulation model and its application for estimating saturation flow at signalised intersection, International Journal for Traffic and Transport Engineering, 1(4): 320-338.

Amita, J.; Singh, J.S.; Kumar, G.P. 2015. Prediction of bus travel time using artificial neural network, International Journal for Traffic and Transport Engineering, 1(5): 410-424.

Aydın, M.M.; Topal, A.; Tanyel, S. 2013. Çok şeritli yollarda yol yüzey bozukluklarının sürücü davranışları üzerindeki etkisinin incelenmesi, TMMOB 10: Ulaştırma Kongresi, 25-27 Eylül 2013, İzmir, Turkey, 413-425. (in Turkish)

Aydın, M.M.; Yildirim, M.S.; Karpuz, O.; Ghasemlou, K. 2014. Modeling of driver lane choice behavior with artificial neural networks (ann) and linear regression (1r) analysis on deformed roads, Computer Science \& Engineering: An International Journal, 4(1): 47-57.

Aydın, M.M.; Topal, A. 2016. Effect of road surface deformations on lateral lane utilization and longitudinal driving behaviors, Journal of Transport, 31(2): 192-201.

Ben-Edigbe, J.; Ferguson, N. 2005. Extent of capacity loss resulting from pavement distress. In Proceedings of the Institution of Civil Engineers - Transport, 158(1): 27-32. 
Ben-Edigbe, J. 2010. Assessment of speed, flow and density functions under adverse pavement conditions, International Journal of Sustainable Development and Planning, 5(3): 1-12.

Ben-Edigbe, J.E.; Ferguson, N.S. 2009. Qualitative road service reduction resulting from pavement distress. In Proceedings of the WIT International Conference on Urban Transport, Bologna, Italy.

Ben-Edigbe, J.E.; Mashros, N.; Minhans, A. 2011. Exploration of trapezoidal flowrate contractions resulting from pavement distress, Journal of Emerging Trends in Engineering and Applied Sciences, 2(2): 351-354.

Daganzo, C.F. 1994. The cell transmission model: a dynamic representation of highway traffic consistent with the hydrodynamic theory, Transportation Research Part B: Methodological, 28(4): 269-287.

Daganzo, C.F. 1993. The cell transmission model part i: a simple dynamic representation of highway traffic. Research Report UCB-ITS-PATH-RR-93-7, University of California, Berkeley, USA.

Daganzo, C.F. 1995. The cell transmission model. part 11: network traffic, Transportation Research Part B: Methodological, 29(2): 79-93.

Dong, H.; Ma, S.; Guo, M.; Liu, D. 2012. Research on analysis method of traffic congestion mechanism based on improved cell transmission model, Discrete Dynamics in Nature and Society, $11 \mathrm{p}$.

Ghasemlou, K.; Aydın, M.M.; Tanyel, S.; Topal, A.; Çalışkanelli, S.P. 2012. Effect of dwell time on performance of signalized intersections. In Proceedings of the 10th International Congress on Advances in Civil Engineering, Middle East Technical University, Ankara, Turkey.
Ghasemlou, K.; Topal, A.; Tanyel, S.; Aydın, M.M.; Afshar, A.A.K. 2014. Investigation the effect of heavy vehicles on capacity of signalized intersections based on bayes' theorem. In Proceedings of the 2 nd the Transportation and Development Institute (T $\bullet D I$ ) Congress, ASCE, Orlando, Florida, USA.

Ghasemlou, K.; Aydın, M.M.; Yildirim, M.S. 2015. Comparison of delay time models for over-saturated traffic flow conditions at signalized intersections, International Journal of Advanced Science and Technology, 84: 9-18.

Gomes, G.; Horowitz, R. 2006. Optimal freeway ramp metering using the asymmetric cell transmission model, Transportation Research Part C: Emerging Technologies, 14(4): 244-262.

Gomes, G.; Horowitz, R.; Kurzhanskiy, A.A.; Varaiya, P.; Kwon, J. 2008. Behavior of the cell transmission model and effectiveness of ramp metering, Transportation Research Part C: Emerging Technologies, 16(4): 485-513.

Li, Z. 2010. Modeling arterial signal optimization with enhanced cell transmission formulations, Journal of Transportation Engineering, 137(7): 445-454.

Lighthill, M.J.; Whitham, G.B. 1955. On kinematic waves: ii. a theory of traffic flow on long crowded roads. In Proceedings of the Royal Society of London, (Series A), 229(1178): 317-345.

Richards, P.I. 1956. Shock waves on the highway, Operations Research, 4(1): 42-51.

Rodriguez-Seda, J.D.; Benekohal, R.F. 2006. Methodology for delay-based passenger car equivalencies for urban transit buses, Transportation Research Record: Journal of the Transportation Research Board, 1988: 127-137. 
Tampère, C.M.; Corthout, R.; Cattrysse, D.; Immers, H.S. 2011. A generic class of first order node models for dynamic macroscopic simulation of traffic flows, Transportation Research Part B: Methodological, 45(1): 289-309.

TCQSM 2013. 3rd Edition, TCRP Report 100. Washington: Transit Cooperative Research Program, Transportation Research Board.

TRB 1950. Highway Capacity Manual, National Research Council, Washington D.C., U.S.A.

TRB 1965. Highway Capacity Manual, National Research Council, Washington D.C., U.S.A.
TRB 2010. Highway Capacity Manual, National Research Council, Washington D.C., U.S.A.

TRL 1991. Towards safer roads in developing countries, Crowthorne, England.

Wong, S.C.; Yang, H.; Au Yeung, W.S.; Cheuk, S.L.; Lo, M.K. 1998. Delay at signal-controlled intersection with bus stop upstream, Journal of Transportation Engineering, 124(3): 229-234.

Zhang, X.; He, R.; Shi, Q.; Ban, J.; Ran, B. 2013. Critical traffic control locations for emergency evacuation, Journal of Transportation Engineering, 139(10): 1030-1038. 